OPEN ACCESS

Edited by:

Liqiang Wang,

Shanghai Jiao Tong University, China

Reviewed by:

Ricardo Emilio Aristizabal-Sierra

University of Antioquia, Colombia

Sung Bo Lee,

Seoul National University, South Korea

*Correspondence:

Myeong-heom Park

park.myeongheom.8r@kyoto-u.ac.jp

Speciality section:

This article was submitted to

Structural Materials,

a section of the journal

Frontiers in Materials

Received: 10 September 2020 Accepted: 09 November 2020

Published: 26 November 2020

Citation:

Park M, Shibata A and Tsuji N (2020) Challenging Ultra Grain Refinement of Ferrite in Low-C Steel Only by Heat Treatment.

Front. Mater. 7:604792.

doi: 10.3389/fmats.2020.604792

\section{Challenging Ultra Grain Refinement of Ferrite in Low-C Steel Only by Heat Treatment}

\author{
Myeong-heom Park ${ }^{1 *}$, Akinobu Shibata ${ }^{1,2,3}$ and Nobuhiro Tsuji ${ }^{1,2}$ \\ ${ }^{1}$ Elements Strategy Initiative for Structural Materials (ESISM), Kyoto University, Kyoto, Japan, ${ }^{2}$ Department of Materials Science \\ and Engineering, Kyoto University, Kyoto, Japan, ${ }^{3}$ Research Center for Structural Materials, National Institute for Materials \\ Science (NIMS), Tsukuba, Japan
}

It is well-known that grain refinement is one of the most effective ways to improve strength of metals without addition of alloying elements. In order to obtain bulky metals having ultrafine grained (UFG) microstructures with average grain sizes smaller than $1 \mu \mathrm{m}$, severe plastic deformation (SPD) processes have made a great success. However, there are still big barriers to realize UFG metallic materials, especially UFG steels, in large scale industries, since severe plastic deformation processes usually need special techniques and equipment, and large deformation forces are required for heavy plastic deformations. Cyclic heat treatments to repeat martensitic transformation and austenitization have been known as a simple way to fabricate fine-grained austenitic structures in steels. In the present study, we tried to make final ferrite microstructures ultrafine in a low-C steel by means of the cyclic heat treatment. Evolution of microstructures during the cyclic heat treatment was systematically investigated, putting stress on the change of grain sizes of austenite and ferrite. The austenite grain size decreased with increasing the number of heat treatment cycles, and the minimum average austenite grain size obtained was $11 \mu \mathrm{m}$. By having furnace-cooling from austenite states with various grain sizes, ferrite microstructures with different mean grain sizes were fabricated. We could successfully obtain a fine-grained ferrite structure with a mean grain size of $4.5 \mu \mathrm{m}$ and nearly a random texture through the heat treatment without deformation. Microstructural features and mechanical properties of the obtained fine-grained ferritic structures were investigated by scanning electron microscope/electron back-scattering diffraction measurements and a tensile test at room temperature. The specimens with ferrite + pearlite microstructure with the smallest average ferrite grain size of $4.5 \mu \mathrm{m}$ managed both high strength (yield strength of $375 \mathrm{MPa}$ and tensile strength of $500 \mathrm{MPa}$ ) and large tensile ductility (uniform elongation of $20 \%$ and total elongation of $39 \%$ ) in the simple $2 \mathrm{Mn}-0.1 \mathrm{C}$ steel.

Keywords: ultrafine grained ferritic steel, refinement of austenite, low-carbon steel, cyclic heat treatment, mechanical properties 


\section{INTRODUCTION}

Almost all the metallic materials used for practical applications are polycrystalline materials composed of a number of grains. It has been known that the grain size of polycrystalline metals affects their strength, according to the well-known Hall-Petch relationship (Hall, 1951; Petch, 1953), expressed as:

$$
\sigma_{y}=\sigma_{0}+k_{y} d^{-\frac{1}{2}}
$$

where $\sigma_{y}$ is the yield strength of the polycrystalline metal, $\sigma_{0}$ the friction stress (a constant), $k_{y}$ the Hall-Petch constant and $d$ the mean grain size. According to the Hall-Petch relationship, it is expected to achieve high strength in metallic materials by decreasing the grain size. However, the minimum mean grain sizes in commercial metals having bulky dimensions have been around $10 \mu \mathrm{m}$ by now. For obtaining bulky materials with much finer grains, a variety of efforts have been made for a long time. Severe plastic deformation (SPD) is known as one of the promising methods for achieving ultrafine grain sizes smaller than $1 \mu \mathrm{m}$, through accumulating lattice defects in materials by applying extremely large plastic deformation (Stolyarov et al., 2001; Tsuji et al., 2002; Son et al., 2005; Azushima et al., 2008; Okayasu et al., 2008; Tsuji et al., 2008; Calcagnotto et al., 2010; Mohamed et al., 2015; Amani et al., 2017). However, most SPD processes do not seem applicable to practical manufacturing in large scales, due to their complicated procedures, limited dimensions of specimens and huge metal-working forces required. Indeed, even in the laboratory scale, SPD processes are mostly applicable to easily deformable materials such as nonferrous metals (aluminum or copper) or ultra-low carbon interstitial-free steels due to a limited working force in machines or fracture of materials happening during the processes. Consequently, grain refinement of metals having higher strengths (e.g., steels) still relies on conventional heavy deformation plus subsequent annealing or by thermomechanically controlled processes (Okitsu et al., 2009; Tsuji et al., 2019). On the other hand, an alternative way utilizing cyclic transformation between martensite and austenite was established by Grange to make austenite grain sizes in steels smaller than 1-2 $\mu \mathrm{m}$ without deformation (Grange, 1971). Shibata et al. (2013) used the cyclic heat treatment for refining austenite grain sizes in medium carbon steels and could obtain the austenite grain size of 4.5 and $2.4 \mu \mathrm{m}$ in a $0.44 \mathrm{C}-0.86 \mathrm{Mn}$ (mass $\%)$ steel and a $0.46 \mathrm{C}-0.84 \mathrm{Mn}-0.3 \mathrm{~V}$ steel, respectively. Furuhara et al. (2008) used a cyclic heat treatment followed by air-cooling and reported that fine-grained ferrite having a grain size of $2.2 \mu \mathrm{m}$ was successfully obtained in a medium-carbon steel with a chemical composition of Fe-0.35C-1.05Cr-0.17Mo (in mass\%). Although fine grained microstructures have been successfully obtained in medium carbon steels by the cyclic heat treatments, there are few studies on microstructure refinement in low-carbon steels with $\sim 0.1$ mass $\%$ C contents by such cyclic processes, probably due to their higher $\mathrm{A}_{\mathrm{e} 3}$ temperatures. The relatively high $\mathrm{A}_{\mathrm{e} 3}$ temperatures of low-carbon steels easily enhance grain growth of austenite, which may also cancel out the grain refinement effect in cyclic heat treatments. The low hardenability of low-carbon steels might be another barrier to obtain fully martensitic structures especially from refined austenite having a high density of nucleation sites (i.e., austenite grain boundaries) for ferrite transformation during cooling. However, low-C steels are widely used for practical applications, for example in the automobile industries where further strengthening of steels is required in recent years. In the present study, we investigate the possibility of grain refinement of austenite and ferrite microstructures in a lowcarbon steel by a simple cyclic heat treatment without plastic deformation. Microstructure evolution during the cyclic heat treatment is systematically observed, and mechanical properties of the obtained low-C steel with fine-grained microstructures are compared with those of coarse-grained counterparts.

\section{EXPERIMENTAL PROCEDURE}

\section{Materials and Process}

The material used in the present study is a $2 \mathrm{Mn}-0.1 \mathrm{C}$ (mass\%) steel, of which detailed chemical composition is shown in Table 1. Sheets of the $2 \mathrm{Mn}-0.1 \mathrm{C}$ steel having a dimension of $15 \mathrm{~mm}$ in length, $7 \mathrm{~mm}$ in width and $1 \mathrm{~mm}$ in thickness were provided to the following heat treatments for changing grain sizes of austenite and ferrite. In order to determine austenitizing heat treatment temperature of the present steel, $\mathrm{A}_{\mathrm{e} 3}$ temperature, at which austenite-to-ferrite phase transformation occurs in equilibrium, was calculated to be $804^{\circ} \mathrm{C}$ by the use of Thermo-Calc software. Figure 1 shows two types of heat treatment routes to obtain martensite microstructures with different grain sizes [route $(\mathrm{A})$ ] and ferrite + pearlite $(\mathrm{F}+\mathrm{P})$ microstructures with different ferrite grain sizes [route (B)]. In the route (A), in order to obtain different austenite grain sizes, austenitizing heat treatments were conducted at various temperatures ranging from 1,100 to $830^{\circ} \mathrm{C}$ for $6 \mathrm{~h}$ using a vacuum furnace, followed by waterquenching (W.Q.). In addition, using the obtained specimens austenitized at 950 or $830^{\circ} \mathrm{C}$ for $6 \mathrm{~h}$ and water-quenched, the heat treatment at $810^{\circ} \mathrm{C}$ for $3 \mathrm{~min}$ (for austenitization) and subsequent water-quenching were repeated up to four cycles using a salt bath, for obtaining finer austenite grain sizes. The austenitizing temperature in the cyclic heat treatment $\left(810^{\circ} \mathrm{C}\right)$ was set to be just above the $\mathrm{A}_{\mathrm{e} 3}$ temperature of the present steel. All final specimens obtained in the route (A) had fully martensitic microstructures at room temperature. In the route (B), the austenitizing heat treatment at temperatures ranging from 1,100 to $830^{\circ} \mathrm{C}$ for $6 \mathrm{~h}$ was carried out again, but then furnacecooling at a slow cooling rate of $1^{\circ} \mathrm{C} \mathrm{s}^{-1}$ was conducted after the austenitization to obtain $\mathrm{F}+\mathrm{P}$ structures having different ferrite grain sizes. Specimens austenitized at $830^{\circ} \mathrm{C}$ and water-quenched were provided to the cyclic heat treatment. In the cyclic heat

\begin{tabular}{|c|c|c|c|c|c|}
\hline C & Mn & Si & $\mathbf{P}$ & $\mathbf{S}$ & $\mathrm{Fe}$ \\
\hline 0.103 & 2.00 & 0.01 & $<0.002$ & 0.0008 & Bal \\
\hline
\end{tabular}


treatment at $810^{\circ} \mathrm{C}$ for $3 \mathrm{~min}$, the specimens were air-cooled only after the last (the fourth) austenitizaition at $810^{\circ} \mathrm{C}$ in order to obtain $\mathrm{F}+\mathrm{P}$ microstructures with finer ferrite grain sizes.

\section{Microstructure Observation}

For microstructure observations, specimens were mechanically polished by emery paper (\#120-4000), and then electrically polished in a solution of $10 \mathrm{vol} \%$ of $\mathrm{HClO}_{4}$ and $90 \mathrm{vol} \%$ of $\mathrm{CH}_{3} \mathrm{COOH}$ with a voltage of $22 \mathrm{~V}$ for $30 \mathrm{~s}$ at room temperature. Microstructural and crystallographic features of the martensite and $\mathrm{F}+\mathrm{P}$ microstructures were characterized by using a fieldemission scanning electron microscope (FE-SEM, JSM-7100F, JEOL) equipped with an electron back-scattering diffraction (EBSD) system operated at an accelerating voltage of $15 \mathrm{kV}$. The EBSD orientation mapping and analysis by OIM (Orientation Imaging Microscopy) system were performed to characterize grain boundaries and textures in the microstructures. For the precise EBSD measurement of martensite structures, we examined sufficiently wide regions of about $300 \mu \mathrm{m} \times 900$ with small step sizes of $0.42-0.27 \mu \mathrm{m}$. In the EBSD measurement of the $\mathrm{F}+\mathrm{P}$ structures, different sizes of region ranging from about $900 \mu \mathrm{m} \times$ $2,700 \mu \mathrm{m}-300 \mu \mathrm{m} \times 900 \mu \mathrm{m}$ and different step sizes ranging from 0.88 to $0.28 \mu \mathrm{m}$ were used depending on their ferrite grain size. For the martensitic microstructures, prior austenite grain boundaries were identified by morphological features of martensite observed on EBSD image quality (IQ) maps and crystallographic characteristics based on Kurdjumov-Sachs (K-S) orientation relationship between austenite and martensite. Average prior-austenite grain sizes in the martensite microstructures and ferrite grain sizes in the $\mathrm{F}+\mathrm{P}$ microstructures were measured by a linear interception method on EBSD grain boundary maps. Average block size (thickness) in the martensite structures was also measured based on EBSD orientation color maps because the blocks were the aggregates of laths having nearly the same orientation (nearly the same color on EBSD orientation color maps).

\section{Tensile Tests}

In order to evaluate mechanical properties of the $\mathrm{F}+\mathrm{P}$ microstructures having different ferrite grain sizes, uniaxial tensile tests were carried out at room temperature at an initial strain rate of $8.3 \times 10^{-4} \mathrm{~s}^{-1}$ by the use of a universal tensile testing machine (AG-100kN X plus, Shimadzu). Tensile specimens with a gauge length of $10 \mathrm{~mm}$, width of $5 \mathrm{~mm}$ and thickness of $1 \mathrm{~mm}$ were cut from the heat-treated samples by an electrical discharge cutting machine. An extensometer was attached on the tensile specimen for precisely measuring displacement (and then tensile strains) of the gauge part of the tensile specimen during tensile testing.

\section{RESULTS AND DISCUSSION}

\section{Grain Refinement of Austenite}

Figure 2 shows EBSD orientation color maps of the martensite structure obtained from the austenitizing heat treatment at (A) $1,100^{\circ} \mathrm{C}$, (B) $950^{\circ} \mathrm{C},(\mathrm{C}) 900^{\circ} \mathrm{C}$, and (D) $830^{\circ} \mathrm{C}$ for $6 \mathrm{~h}$ followed by
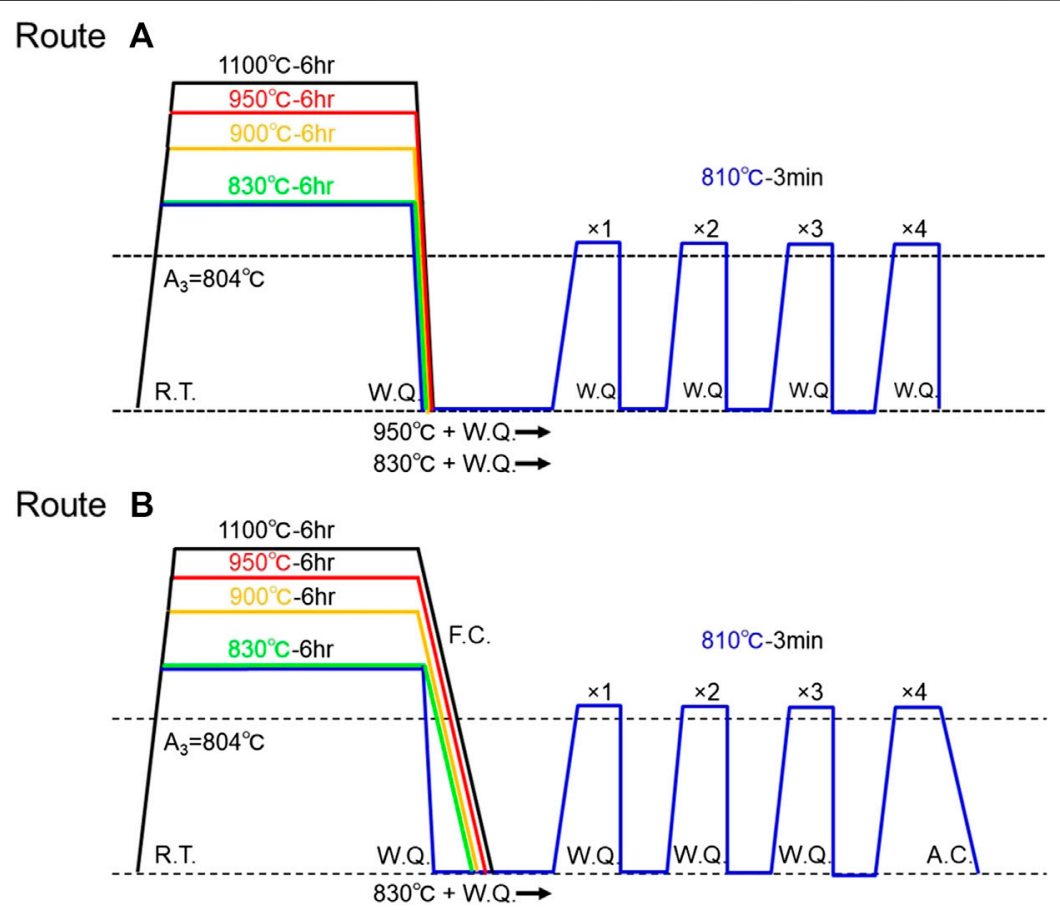

FIGURE 1 | Schematic representations showing the heat treatment routes to obtain austenite microstructures with different grain sizes [route (A)] and ferrite + pearlite $(F+P)$ microstructures with different ferrite grain sizes [route $(\mathbf{B})$ ] in the $2 \mathrm{Mn}-0.1 \mathrm{C}$ steel. In the route (A), final microstructures at room temperature were martensite. 


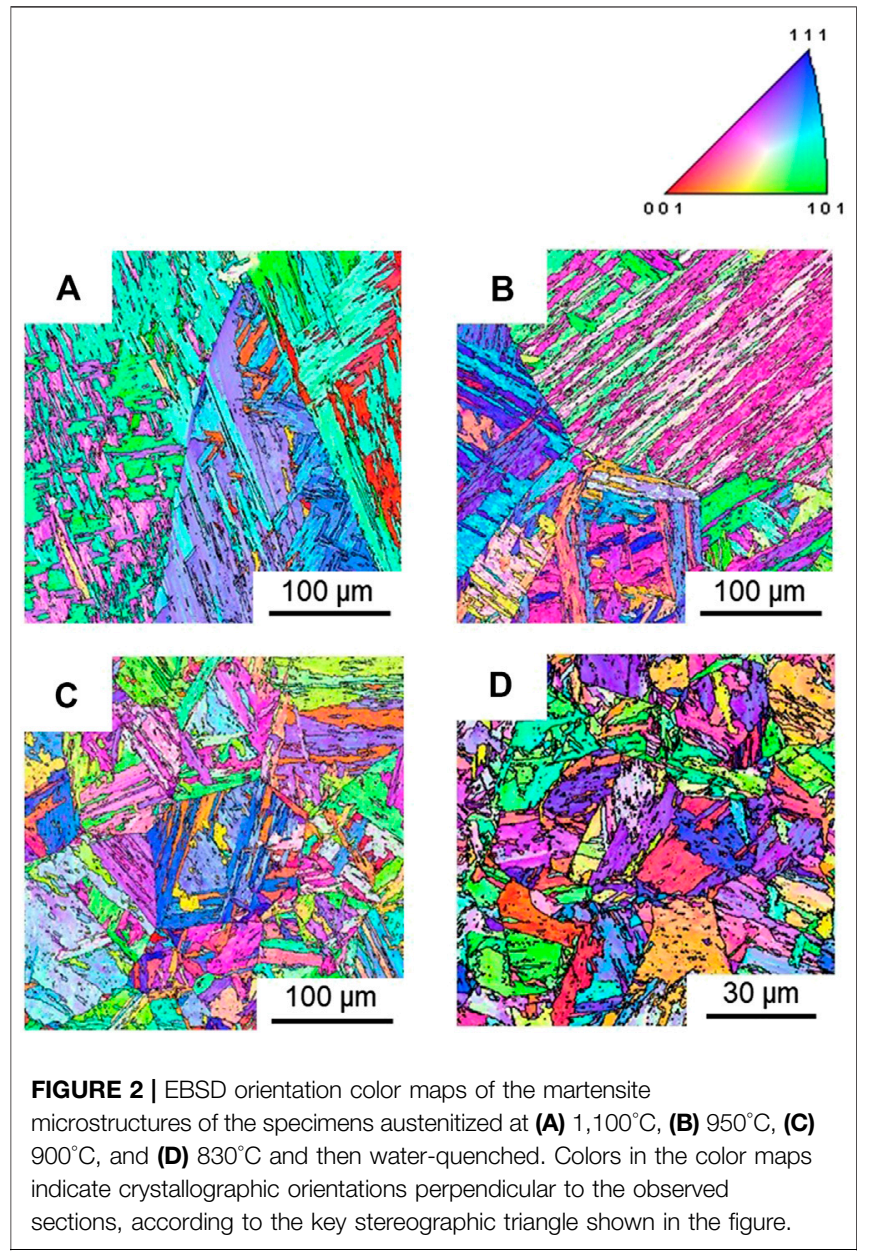

water-quenching, with respect to the route (A) illustrated in Figure 1. Colors in the EBSD maps indicate crystallographic orientations perpendicular to the observed sections, according to the key stereographic triangle shown in Figure 2. It was confirmed that all the specimens had fully martensitic microstructures of typical lath martensite consisting of lathes (single crystals of martensite), blocks (aggregates of laths with nearly the same orientation, thus units showing the same colors on EBSD orientation maps), packets (aggregates of blocks with the same habit plane), all formed within each prior-austenite grain. It is known that prior-austenite grain boundaries are preserved in martensitic transformation, since martensite crystals do not grow over prior-austenite grain boundaries. Therefore, prior-austenite grain sizes could be identified even on fully martensitic microstructures like Figure 2. The average prior austenite grain sizes with standard deviations of the specimens austenitized at (A) $1,100^{\circ} \mathrm{C}$, (B) $950^{\circ} \mathrm{C}$, (C) $900^{\circ} \mathrm{C}$, and (D) $830^{\circ} \mathrm{C}$ were $475 \pm 63.4 \mu \mathrm{m}, 244 \pm 34.5 \mu \mathrm{m}, 78.4 \pm 11.1$, $28.6 \pm 3.8 \mu \mathrm{m}$, respectively. The austenite grain size decreased with decreasing the austenitization temperature, as shown in Figure 3. It was found from Figure 2 that the martensite structures austenitized at lower temperatures showed finer blocks. The average block sizes with standard deviations in the specimens austenitized at (A) $1,100^{\circ} \mathrm{C}$, (B) $950^{\circ} \mathrm{C}$, (C) $900^{\circ} \mathrm{C}$, and

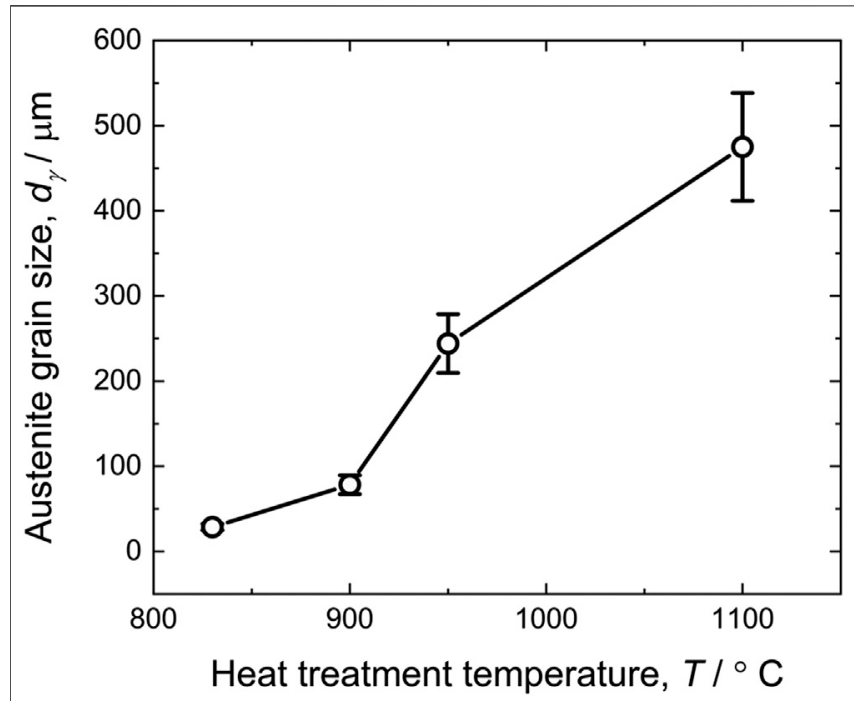

FIGURE 3 | Austenite grain sizes in the specimens simply austenitized and water-quenched, plotted as a function of the austenitizing temperatures.

(D) $830^{\circ} \mathrm{C}$ were $18.1 \pm 1.91 \mu \mathrm{m}, 16.5 \pm 2.79 \mu \mathrm{m}, 13.0 \pm 2.43 \mu \mathrm{m}$, $6.6 \pm 1.21 \mu \mathrm{m}$, respectively.

The minimum austenite grain size obtained from the simple austenitization heat treatment at different temperatures was $28.6 \mu \mathrm{m}$, as was mentioned above. In order to obtain furthermore refined austenite grains, the cyclic heat treatment mentioned above was carried out. The cyclic heat treatment (the route (A) in Figure 1) was applied to the specimens austenitized at $950^{\circ} \mathrm{C}$ or $830^{\circ} \mathrm{C}$ and water-quenched (corresponding to Figures 2B,D, respectively). The austenite grain sizes of the starting specimens austenitized at 950 and $830^{\circ} \mathrm{C}$ were $244 \mu \mathrm{m}$ [(Figure 2B) and $28.6 \mu \mathrm{m}$ (Figure 2D)], respectively. Figures 4A,B display EBSD orientation maps of the specimens after each cycle of the repetitive heat treatment at $810^{\circ} \mathrm{C}$ for $3 \mathrm{~min}$ followed by water-quenching. The rows of maps (A) and (B) in Figure 4 correspond to the starting martensite-structured specimens austenitized at $950^{\circ} \mathrm{C}$ and $830^{\circ} \mathrm{C}$, respectively, and waterquenched. Figures $4 \mathrm{~A}, \mathrm{~B}$ indicate that the austenite grain size decreased with increasing the number of the cyclic heat treatment. The change in the austenite grain size in the cyclic heat treatment is summarized in Figure 4C. In case of the starting specimen austenitized at $950^{\circ} \mathrm{C}$, the austenite grain size was significantly refined from 244 to $36.0 \mu \mathrm{m}$ by the one cycle of the heat treatment. Then, the austenite grain size gradually (but not so greatly) decreased with increasing the number of the heat treatment cycle. For the specimen austenitized at $830^{\circ} \mathrm{C}$ that already had a relatively fine austenite grain size $(28.6 \mu \mathrm{m})$, the change of the austenite grain size was not significant but the grain size gradually decreased with the progress of the cyclic heat treatment. After fourth cycle, the austenite grain size of the specimens austenitized at 950 and $830^{\circ} \mathrm{C}$ plus water-quenched was 11.9 and $11.1 \mu \mathrm{m}$, respectively. It was confirmed by the experiments that the cyclic heat treatment could refine the austenite grain size down to about $11 \mu \mathrm{m}$ in the low-C steel. 


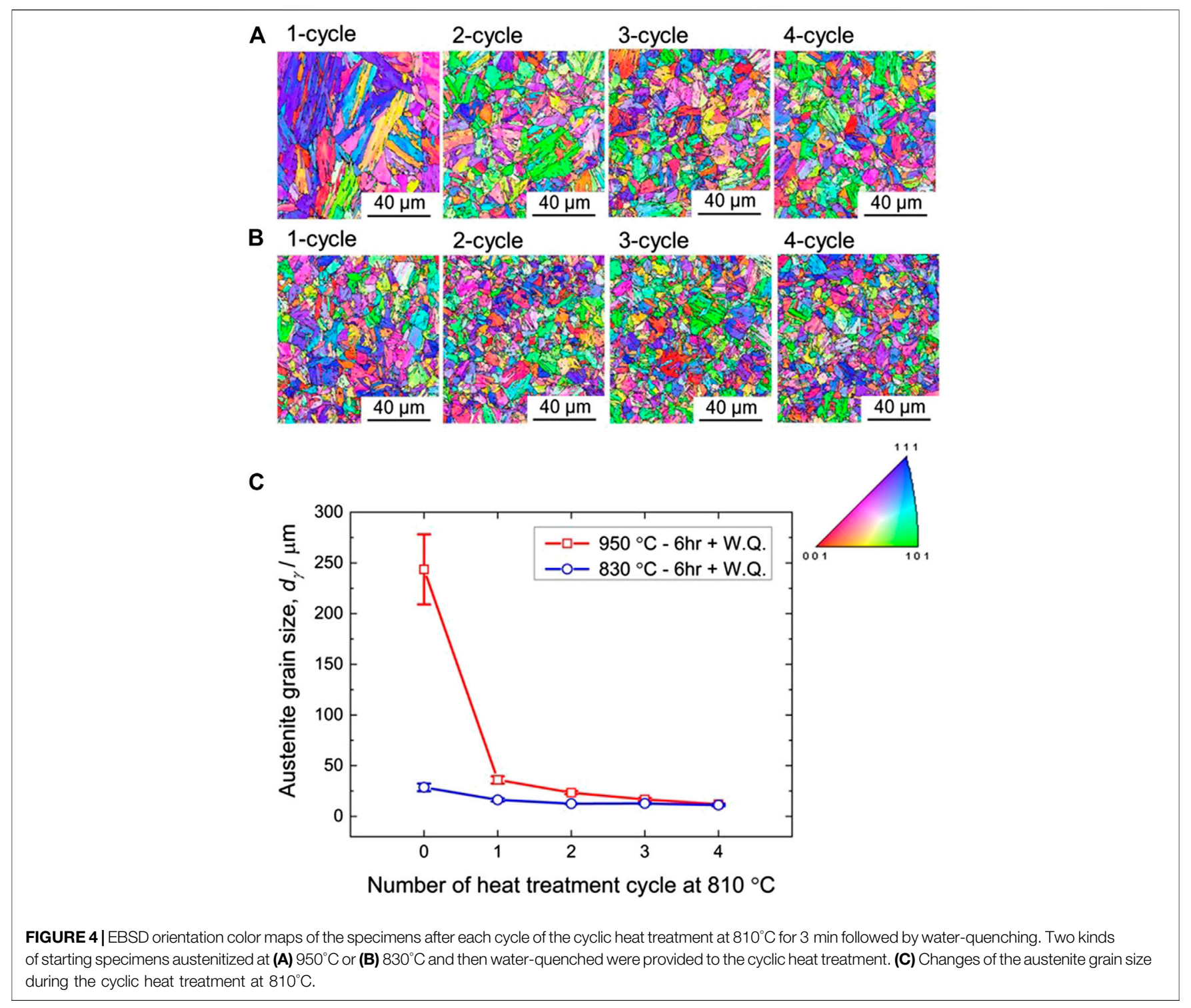

Based on the results shown in Figure 4, the process of austenite grain refinement in the cyclic heat treatment is schematically illustrated in Figure 5. It is known that the lath martensite in carbon steels contains high density of dislocations and high-angle grain boundaries, i.e., block-boundaries, packet-boundaries, and prior-austenite grain boundaries (Figure 5A) (Morito et al., 2006). These lattice defects can act as nucleation sites of austenite upon heating up to a temperature above $A_{\mathrm{e} 3}$. Especially, triple junctions of such grain boundaries would be the most preferable nucleation sites of austenite (Figure 5B). Because of the high density of austenite nucleation sites in the lath martensite, the austenite grain size could be significantly refined by the first cycle of the heat treatment (Figure 5C), as was observed in Figure 4C. The martensite microstructure transformed from such refined austenite become finer than the initial martensite microstructure (Figure 5D), and provide more nucleation sites for austenite in the next cycle of the heat treatment. This is the reason why the austenite grain size gradually decreased by the cyclic heat treatment.

\section{Grain Refinement of Ferrite + Pearlite Microstructures}

In the previous section, it was shown that the austenite grain size of the low-C steel could be refined down to $11 \mu \mathrm{m}$ by the simple cyclic heat treatment without plastic deformation. When ferritic transformation happens from austenite, preferential nucleation sites for ferrite would be grain boundaries of austenite (Furuhara et al., 2003; Yin et al., 2017). Thus, the grain refinement of ferrite is expected when the austenite grain size is refined. We investigated the grain refinement of ferrite by the use of the route (B) heat treatment illustrated in Figure 1 where furnacecooling or air-cooling was applied after the final austenitization in the route (A) heat treatment. Figure 6 exhibits EBSD orientation 


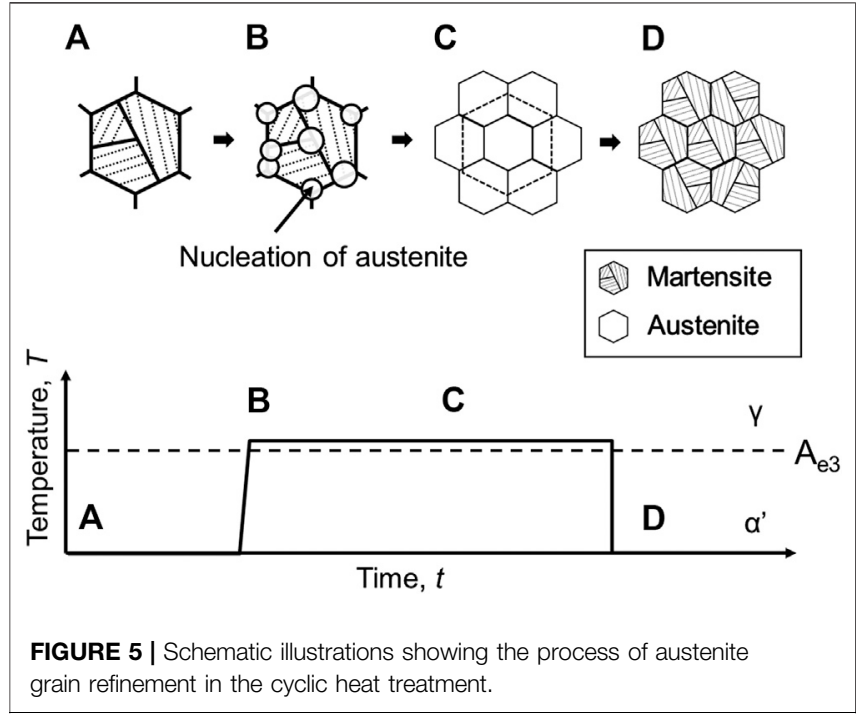

color maps and corresponding 001 pole figures of the specimens obtained by route (B) heat treatment. Figures 6A-D correspond to the specimens simply austenitized at different temperatures, i.e., (A) $1,100^{\circ} \mathrm{C}$, (B) $950^{\circ} \mathrm{C},(\mathrm{C}) 900^{\circ} \mathrm{C}$, and (D) $830^{\circ} \mathrm{C}$ for $6 \mathrm{~h}$ followed by furnace-cooling. All the specimens showed ferrite + pearlite $(\mathrm{F}+\mathrm{P})$ microstructures, although the area fraction of pearlite in this low-C steel with $0.1 \% \mathrm{C}$ was relatively small ( $20 \%)$. The average ferrite grain sizes measured from EBSD maps were $89.9 \pm 20.9 \mu \mathrm{m}, 47.5 \pm 13.0 \mu \mathrm{m}, 22.1 \pm 2.4 \mu \mathrm{m}$, and
$10.3 \pm 2.0 \mu \mathrm{m}$ in the specimens austenitized at (A) $1,100^{\circ} \mathrm{C}$, (B) $950^{\circ} \mathrm{C}$, (C) $900^{\circ} \mathrm{C}$, and (D) $830^{\circ} \mathrm{C}$, respectively. With decreasing the austenitization temperature, i.e., with decreasing the prior austenite grain size as was shown in the former section, the ferrite grain size monotonously decreased. Further grain refinement was tried by adopting air-cooling after the final austenitization in the cyclic heat treatment. Figure $6 \mathrm{E}$ shows the specimen cyclically heat-treated at $810{ }^{\circ} \mathrm{C}$ for $3 \mathrm{~min}$ up to four cycles, followed by aircooling. As was shown in the former section, the cyclic heat treatment could reduce the austenite grain size down to $11.1 \mu \mathrm{m}$. After this heat treatment without plastic deformation, the finest average ferrite grain size of $4.5 \mu \mathrm{m}$ was achieved. It was found from the 011 pole figures shown in Figure 6 that the ferrite microstructures had weak textures. Although the coarse-grained specimen with the ferrite grain size of $89.9 \mu \mathrm{m}$ (Figure 6A) showed some strong intensities in the pole figure, it was probably because the number of grains $\left(n_{\mathrm{G}}\right)$ included in the observed area was too small $\left(n_{\mathrm{G}}=27\right)$ to obtain statistically reliable texture data, compared to other specimens having average ferrite grain sizes of $47.5 \mu \mathrm{m}$ (Figure 6B; $n_{\mathrm{G}} \sim 96$ ), $22.1 \mu \mathrm{m}[(\mathrm{C})$; $\left.n_{\mathrm{G}} \sim 170\right], 10.3 \mu \mathrm{m}\left[(\mathrm{D}) ; \mathrm{n}_{\mathrm{G}} \sim 270\right]$ and $4.5 \mu \mathrm{m}\left[(\mathrm{E}) ; \mathrm{n}_{\mathrm{G}} \sim 7,700\right]$. Considering that conventional thermomechanical processing involving plastic working used to result in more or less textured materials, it is noteworthy that the specimens having finer ferrite grain sizes showed nearly random texture and it is generally difficult to obtain fine-grained ferrite microstructures with random texture in steels. Figure 7 shows the relationship between the average ferrite grain size obtained and the grain size of the prior-austenite from which ferrite formed. The ferrite grain

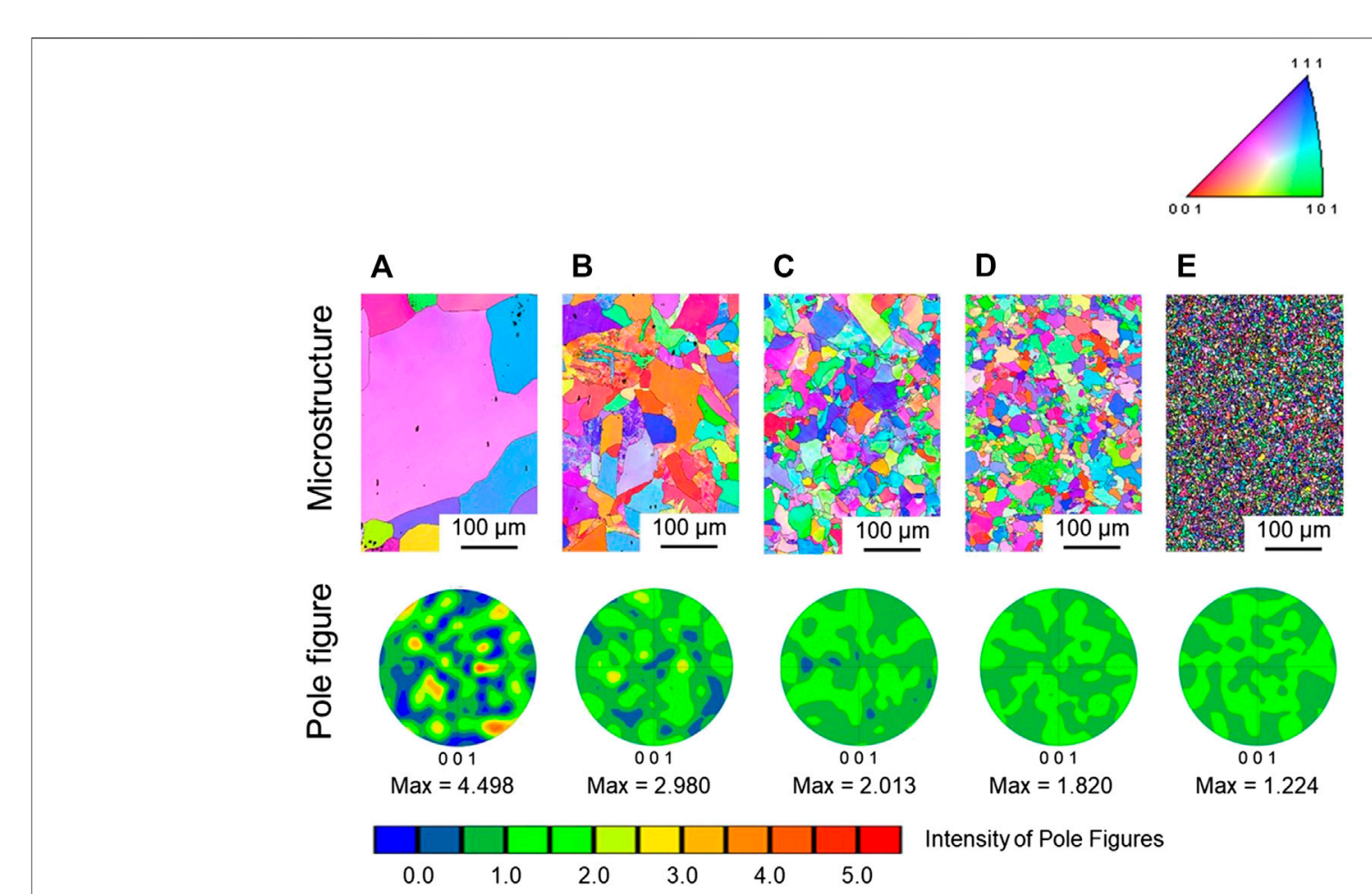

FIGURE 6 | EBSD orientation color maps and corresponding 001 pole figures of the specimens simply austenitized at (A) $1,100^{\circ} \mathrm{C}$, (B) $950^{\circ} \mathrm{C}$, (C) $900^{\circ} \mathrm{C}$, and (D) $830^{\circ} \mathrm{C}$ for $6 \mathrm{~h}$ followed by furnace-cooling, and the specimen (E) cyclic heat-treated at $810^{\circ} \mathrm{C}$ up to four cycles followed by air-cooling. 


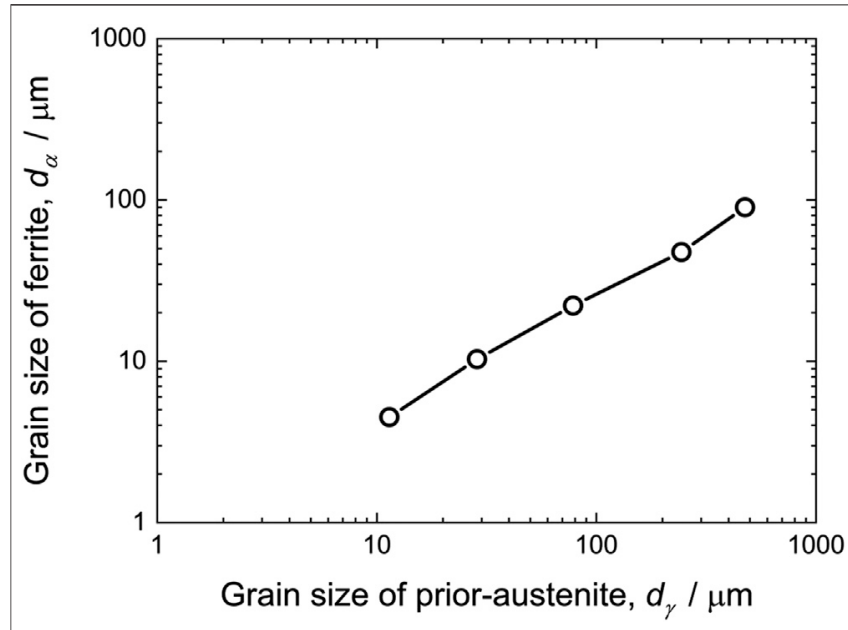

FIGURE 7 | Relationship between the average ferrite grain size $\left(d_{\alpha}\right)$ and the average prior-austenite grain size $\left(d_{\alpha}\right)$ in the specimen shown in Figure 6.

size monotonously decreased with decreasing the prior-austenite grain size. It is noteworthy that the ferrite grain size became always finer than the prior-austenite grain size.
We also studied features of pearlite in the $\mathrm{F}+\mathrm{P}$ specimens furnace-cooled or air-cooled after the austenitization in the route (B) process shown in Figure 1. Figure 8 represents SEM images of the specimens with $\mathrm{F}+\mathrm{P}$ microstructures simply austenitized at $(\mathrm{A}$, D) $950^{\circ} \mathrm{C}$ or $(\mathrm{B}, \mathrm{E}) 830^{\circ} \mathrm{C}$ followed by furnace-cooling, and (C, F) the specimen cyclically heat-treated at $810^{\circ} \mathrm{C}$ up to four cycles followed by air-cooling. In the lower magnification images shown in Figures 8A-C, proeutectoid ferrite $(\mathrm{F})$ having dark contrast and pearlite $(\mathrm{P})$ having bright contrast composed of ferrite and cementite $\left(\mathrm{Fe}_{3} \mathrm{C}, \theta\right)$ with typical eutectoid lamellar structures were clearly observed. The area fractions of pearlite observed in the specimens austenitized at $950^{\circ} \mathrm{C}, 830^{\circ} \mathrm{C}$ and cyclically heattreated at $810^{\circ} \mathrm{C}$ were $20.3,22.0$, and $17.5 \%$, respectively. The pearlite exhibited the block structures, each of which should have the same ferrite orientation (Takahashi et al., 1978). The size of pearlite blocks decreased with decreasing the austenitization temperature, i.e., the prior-austenite grain size. SEM images in higher magnifications are shown in Figures 8D-F. In the specimens transformed from austenite with the mean grain size of 244 and $28.6 \mu \mathrm{m}$ (Figures 8D,E, respectively), the pearlite colony having an identical direction of lamellae (Takahashi et al., 1978; Nakada et al., 2009) could be clearly recognized. The size of pearlite colonies was found to become smaller with decreasing the prior-
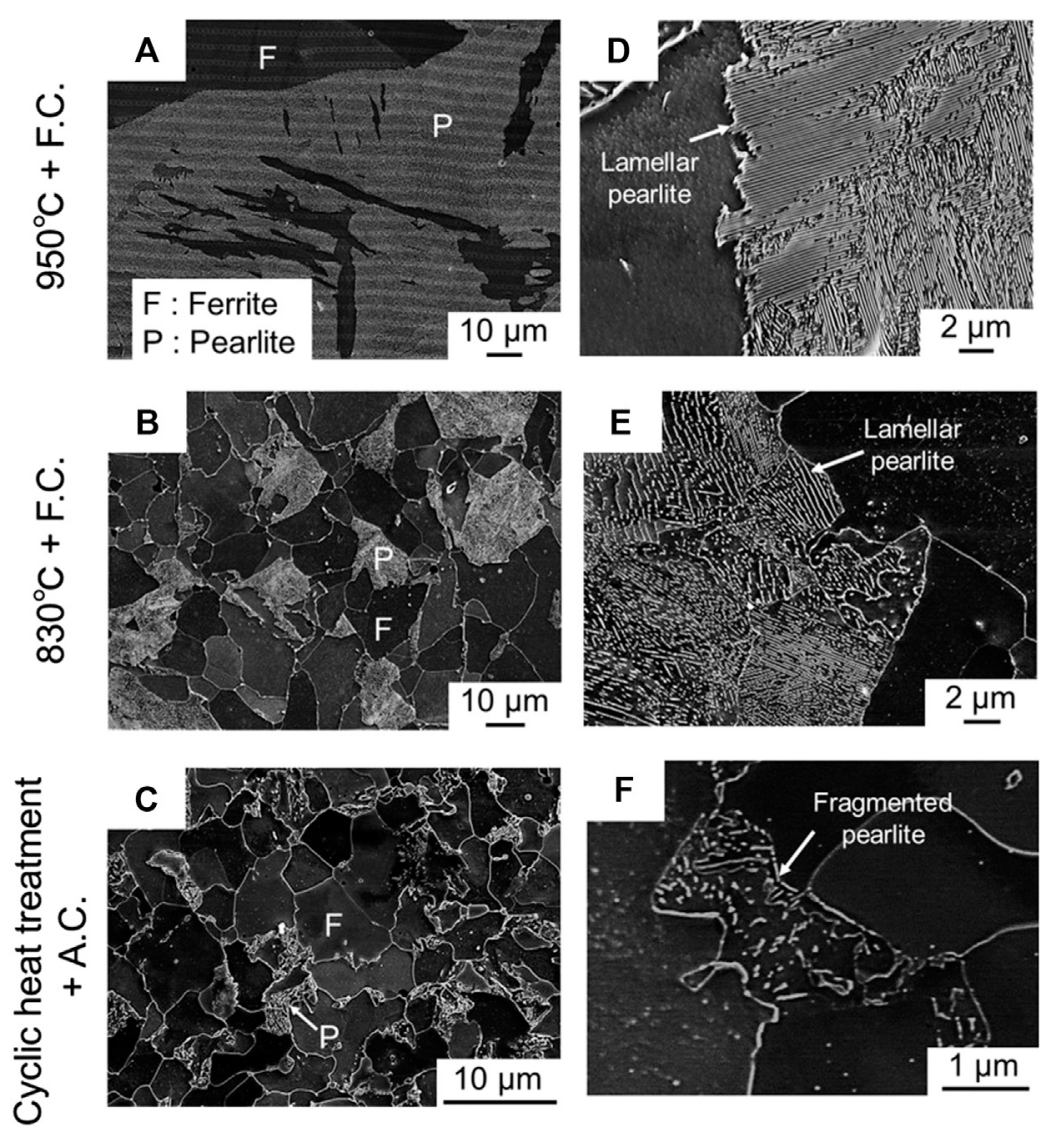

FIGURE 8 | SEM microstructures of the specimens with ferrite + pearlite $(F+P)$ microstructures simply austenitized at $\left(\mathbf{A}\right.$, D) $950^{\circ} \mathrm{C}$ or $\left(\mathbf{B}\right.$, E) $830^{\circ} \mathrm{C}$ followed by furnace-cooling, and (C, F) the F + P specimen cyclic heat-treated at $810^{\circ} \mathrm{C}$ up to four cycles followed by air-cooling. (A-C) lower magnification images, and (D-F) higher magnification images. 


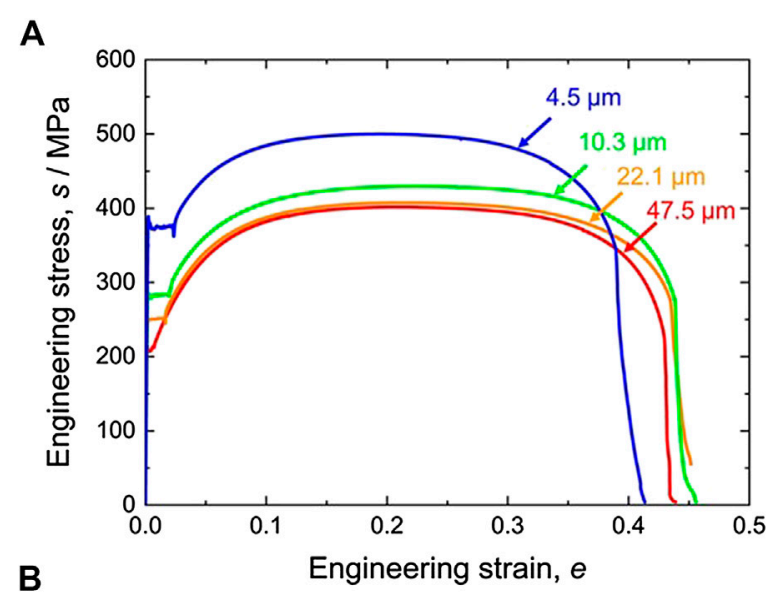

B

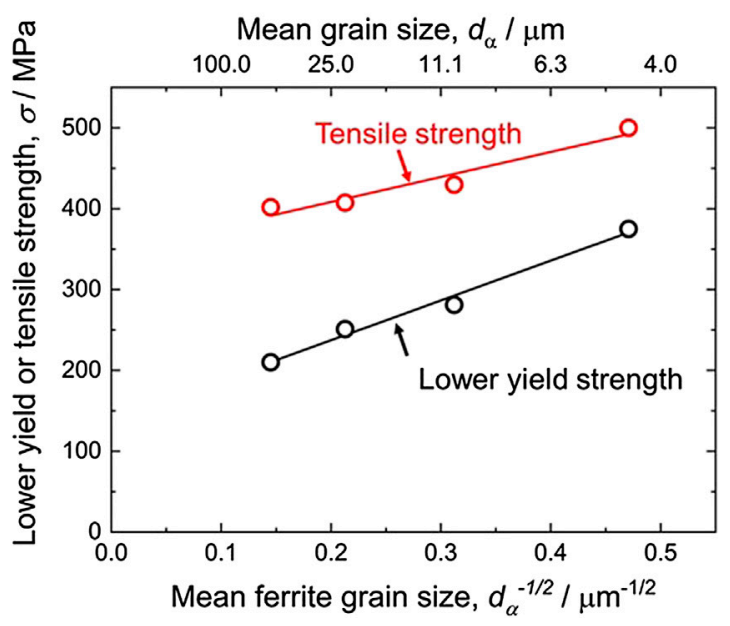

FIGURE 9 | (A) Engineering stress-strain curves of the $F+P$ specimens with different ferrite grain sizes ranging from 47.5 to $4.5 \mu \mathrm{m}$. (B) The yield strength ( $\sigma_{Y}$ : the lower yield stress) and the tensile strength $\left(\sigma_{T S}\right)$ of the $\mathrm{F}+\mathrm{P}$ specimens plotted as a function of the minus square root of the average ferrite grain size (Hall-Petch plots).

austenite grain size. On the other hand, the specimen transformed from the fine-grained austenite with the mean austenite grain size of $11.1 \mu \mathrm{m}$ showed a pearlite structure having significantly different morphology (Figures 8C,F). Instead of the typical lamellar pearlite, the specimen showed the pearlite structures composed of fragmented cementite dispersed in ferrite, as was indicated by the arrow in Figure 8F. Shibata et al. (2013) also observed such a pearlite structure in a medium-carbon steel and explained the formation of fragmented pearlite transformed from fine-grained austenite in the following way. When the austenite grain size is smaller, the distance between neighboring pearlite colonies formed on austenite grain boundaries (or triple junctions of austenite grain boundaries) becomes shorter. High density of austenite grain boundaries in the fine-grained microstructures act as fast paths for diffusion. Under such a situation in the steel having finegrained austenite (like that $d \gamma=11.1 \mu \mathrm{m}$ ), the diffusion field of carbon around neighboring pearlite colonies might be overlapped and become more uniform. Then, ferrite and cementite does not need to grow cooperatively and not need to maintain typical lamellar morphology. This is considered to be the possible reasons for the formation of the fragmented pearlite in the $\mathrm{F}+\mathrm{P}$ microstructure transformed from the finegrained austenite in the present low-C steel.

\section{Mechanical Properties of Ferritic Specimens With Different Grain Sizes}

Figure 9A shows engineering stress-strain curves obtained from the room temperature tensile tests of the specimens having $\mathrm{F}+\mathrm{P}$ microstructures with different ferrite grain sizes ranging from 47.5 to $4.5 \mu \mathrm{m}$. Mechanical properties obtained from the stressstrain curves, i.e., yield strength $\left(\sigma_{\mathrm{Y}}\right)$, tensile strength $\left(\sigma_{\mathrm{TS}}\right)$, uniform elongation $\left(e_{\mathrm{u}}\right)$ and total elongation $\left(e_{\mathrm{t}}\right)$, are summarized in Table 2. Yield-drop was obviously recognized in all the specimens. Thus, the lower yield stress was taken as the yield strength $\left(\sigma_{\mathrm{Y}}\right)$ of the specimens in Table 2. It was found that the yield strength and the tensile strength increased with decreasing the ferrite grain size. The (lower) yield strength and tensile strength of the $4.5 \mu \mathrm{m}$ grain-sized specimen were 375 and $500 \mathrm{MPa}$, respectively. The yield strength $\left(\sigma_{\mathrm{Y}}\right.$ : the lower yield stress) and the tensile strength ( $\left.\sigma_{\mathrm{TS}}\right)$ of the $\mathrm{F}+\mathrm{P}$ specimens were plotted as a function of the minus square root of the average ferrite grain size in Figure 9B. Linear relationships were found in Figure 9B, which meant Hall-Petch relationship stood for the yield strength and the tensile strength. After the yield-drop, the flow stress stayed nearly constant, which corresponded to the Lüders deformation. The yield-drop became more obvious and the length of the flat part, i.e., the Lüders strain, increased with decreasing the ferrite grain size. The Lüders strain in the finegrained $\mathrm{F}+\mathrm{P}$ specimen with the ferrite grain size of $4.5 \mu \mathrm{m}$ was $2.3 \%$, while that in the $47.5 \mu \mathrm{m}$ grain-sized specimen was only $0.7 \%$. In general, Lüders deformation can be understood in terms of Cottrell atmosphere in carbon steels (Cottrell and Bilby, 1949). One possible explanation for the large Lüders strain of the present fine-grained $\mathrm{F}+\mathrm{P}$ specimen is an increase in yield strength by grain refinement. Once the yielding occurs in a localized manner within the Lüders band in the fine-grained $\mathrm{F}+\mathrm{P}$ specimen, the specimen experiences a sudden drop of external stress (i.e., yielddrop) under the tensile deformation at a constant strain rate, as a result of the release of dislocations from Cottrell atmosphere within the Lüders band. For the propagation of the Lüders band, the locally yielded region needs to be strain-hardened to propagate into undeformed region where high stress is required to start plastic deformation. The required strainhardening within the Lüders band would become higher with decreasing the grain size due to the grain-refinement strengthening, so that the region within the Lüders band should be plastically deformed to higher strain. This would be the possible reason why the fine-grained $\mathrm{F}+\mathrm{P}$ specimen had a larger Lüders strain than the coarse-grained specimens. In ductility, on the other hand, it was noteworthy that the uniform elongation of the specimens did not change (20-22\%) in Table 2, even when the ferrite grain size decreased. Figure 10 exhibits strain hardening rate curves, together with true stress- 
TABLE 2 | Mechanical properties of the specimens having ferrite and pearlite $(F+P)$ microstructures with different ferrite grain sizes, obtained by the tensile tests at room temperature.

\begin{tabular}{|c|c|c|c|c|c|}
\hline $\begin{array}{l}\text { Heat treatment } \\
\text { condition }\end{array}$ & $\begin{array}{l}\text { Mean ferrite } \\
\text { grain size, } \\
d_{\mathrm{F}} / \mu \mathrm{m}\end{array}$ & $\begin{array}{c}\text { Yield strength, } \\
\sigma_{\mathrm{Y}} / \mathrm{MPa}\end{array}$ & $\begin{array}{c}\text { Tensile strength, } \\
\sigma_{\mathrm{Ts}} / \mathrm{MPa}\end{array}$ & Uniform elongation, $\mathbf{e}_{\mathrm{u}}$ & Total elongation, $\mathbf{e}_{t}$ \\
\hline $950^{\circ} \mathrm{C}-6 \mathrm{~h}+\mathrm{F} . \mathrm{C}$. & 47.5 & 210 & 401 & 0.21 & 0.46 \\
\hline $900^{\circ} \mathrm{C}-6 \mathrm{~h}+\mathrm{F} . \mathrm{C}$. & 22.1 & 251 & 407 & 0.21 & 0.44 \\
\hline $830^{\circ} \mathrm{C}-6 \mathrm{~h}+\mathrm{F} . \mathrm{C}$. & 10.3 & 281 & 430 & 0.22 & 0.46 \\
\hline $830^{\circ} \mathrm{C}-6 \mathrm{~h}+$ W.Q. and $810^{\circ} \mathrm{C}-3 \mathrm{~min} \times 4+$ A.C. & 4.5 & 375 & 500 & 0.20 & 0.39 \\
\hline
\end{tabular}

The lower yield strength after yield-drop was taken as the yield strength.

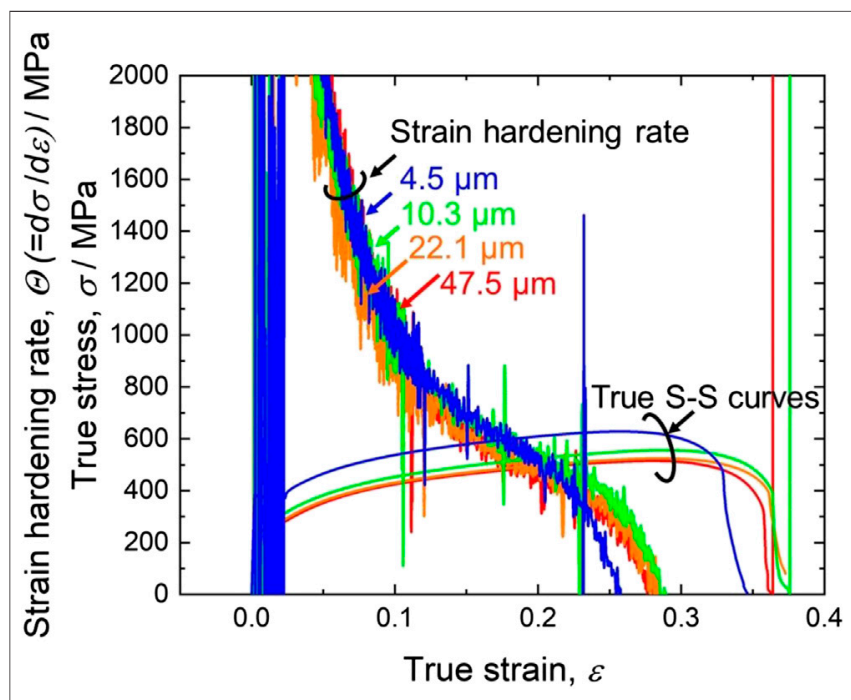

FIGURE 10 | Strain hardening rate curves and true stress-true strain curves of the $\mathrm{F}+\mathrm{P}$ specimens with different ferrite grain sizes ranging from 47.5 to $4.5 \mu \mathrm{m}$.

true strain curves of the $\mathrm{F}+\mathrm{P}$ specimens with different ferrite grain sizes ranging from 47.5 to $4.5 \mu \mathrm{m}$. It was found that the fine-grained F $+\mathrm{P}$ specimen $(4.5 \mu \mathrm{m})$ showed slightly larger strain hardening rate than other coarse-grained specimens until the true strain of about 0.17 . This result suggested that the strain-hardening was not inhibited in the fine-grained specimen, although the flow stress level fairly increased by the grain refinement. The total elongation of the fine-grained specimen (ferrite grain size of $4.5 \mu \mathrm{m}$ ) was smaller than other specimens, but still showed a fairly large value of $39 \%$. It is concluded that a very fine ferrite grain size of $4.5 \mu \mathrm{m}$ could be obtained only by the cyclic heat treatment without plastic working, and the fine-grained $\mathrm{F}+\mathrm{P}$ specimen obtained showed good mechanical properties maintaining high tensile strength of $500 \mathrm{MPa}$ and fairly large tensile elongation of $39 \%$ in the simple $2 \mathrm{Mn}-0.1 \mathrm{C}$ steel. The present study could show a possibility of grain refinement of ferritic structures down to about $4 \mu \mathrm{m}$ in low-C steels by a simple processing without deformation. The yield strength of $375 \mathrm{MPa}$ and the tensile strength of $500 \mathrm{MPa}$ are attractive in low-C steels with simple ferrite microstructures, which cannot be obtained in conventionally coarse-grained ferritic microstructures with grain sizes larger than $10 \mu \mathrm{m}$, as was shown in Figure 9. The nearly random texture obtained in the present fine-grained ferritic steel would be also advantageous for avoiding anisotropic deformation in sheet forming. Additionally, the grain refinement would widen a possibility of further microstructural control using the fine-grained ferrite as a starting microstructure. In fact, we have succeeded in realizing fine-grained dual-phase steels composed of ferrite and martensite with superior mechanical properties compared with conventionally coarse-grained dual-phase steels, which will be shown in our next paper.

\section{CONCLUSION}

In the present study, the possibility of grain refinement of austenite and ferrite in a low-carbon (2Mn-0.1C) steel was investigated by the use of by a simple cyclic heat treatment without plastic working. Microstructure evolution in the low-C steel during the cyclic heat treatment was systematically characterized, and mechanical properties of the obtained specimens were compared. The main results obtained are as follows:

(1) The average austenite grain size decreased with decreasing the austenitization temperature in the simple austenitization and water-quenching heat treatments. The minimum austenite grain size obtained by the simple heat treatment was $28.6 \mu \mathrm{m}$ in the specimen austenitized at $830^{\circ} \mathrm{C}$. Further refinement of austenite down to average grain size of $11 \mu \mathrm{m}$ could be achieved in the $2 \mathrm{Mn}-0.1 \mathrm{C}$ steel by the cyclic heat treatment repeating austenitization from martensite microstructure at $810^{\circ} \mathrm{C}$ for $3 \mathrm{~min}$.

(2) The ferrite + pearlite $(\mathrm{F}+\mathrm{P})$ structures having different average ferrite grain sizes were obtained by furnace- or aircooling from the austenite state with different austenite grain sizes. The average ferrite grain size of the $\mathrm{F}+\mathrm{P}$ microstructures decreased with decreasing the prioraustenite grain size. The finest ferrite grain size of $4.5 \mu \mathrm{m}$ could be obtained by air-cooling of the specimen with the mean prior-austenite grain size of $11 \mu \mathrm{m}$ processed by the cyclic heat treatment up to four cycles. The fine-grained specimen with the mean ferrite grain size of $4.5 \mu \mathrm{m}$ 
transformed from the fine-grained austenite did not show typical pearlite structures with lamellar morphologies, but exhibited fragmented cementite dispersing in the ferrite matrix. The formation of such a fragmented pearlite could be understood in terms of the increased density of nucleation sites (austenite grain boundaries) of pearlite and overlapped diffusion field of carbon atoms.

(3) Mechanical properties of the F + P structures having different ferrite grain sizes were evaluated by tensile tests at room temperature. All the specimens showed a yield-drop followed by Lüders deformation, but the yield-drop became clearer and the Lüders strain was larger in the $\mathrm{F}+\mathrm{P}$ specimens with the finer ferrite grain size. The yield and tensile strengths increased with decreasing the ferrite grain size, and the strengths held Hall-Petch relationships. The fine-grained $\mathrm{F}$ $+\mathrm{P}$ specimen with a ferrite grain size of $4.5 \mu \mathrm{m}$ fabricated by the cyclic heat treatment showed the yield strength of $375 \mathrm{MPa}$ and tensile strength of $500 \mathrm{MPa}$. In spite of the higher strength, the $4.5 \mu \mathrm{m}$ grain-sized specimen showed the same uniform elongation of $\sim 20 \%$ as the coarse-grained specimens, which suggested that the fine-grained specimen maintained good strain-hardening ability.

\section{REFERENCES}

Amani, S., Faraji, G., and Abrinia, K. (2017). Microstructure and hardness inhomogeneity of fine-grained AM60 magnesium alloy subjected to cyclic expansion extrusion (CEE). J. Manuf. Process. 28, 197-208. doi:10.1016/j. jmapro.2017.06.007

Azushima, A., Kopp, R., Korhonen, A., Yang, D. Y., Micari, F., Lahoti, G. D., et al. (2008). Severe plastic deformation (SPD) processes for metals. CIRP Annals 57, 716-735. doi:10.1016/j.cirp.2008.09.005

Calcagnotto, M., Ponge, D., and Raabe, D. (2010). Effect of grain refinement to $1 \mu \mathrm{m}$ on strength and toughness of dual-phase steels. Mater. Sci. Eng. A 527, 7832-7840. doi:10.1016/j.msea.2010.08.062

Cottrell, A. H., and Bilby, B. A. (1949). Dislocation theory of yielding and strain ageing of iron. Proc. Phys. Soc. A 62, 49-62. doi:10.1088/0370-1298/62/1/308

Furuhara, T., Kikumoto, K., Saito, H., Sekine, T., Ogawa, T., Morito, S., et al. (2008). Phase transformation from fine-grained austenite. ISIJ Int. 48, 1038-1045. doi:10.2355/isijinternational.48.1038

Furuhara, T., Yamaguchi, J., Sugita, N., Miyamoto, G., and Maki, T. (2003). Nucleation of proeutectoid ferrite on complex precipitates in austenite. ISIJ Int. 43, 1630-1639. doi:10.2355/isijinternational.43.1630

Grange, R. A. (1971). The rapid heat treatment of steel. Metall. Trans. 2, 65-78. doi:10.1007/BF02662639

Hall, E. O. (1951). The deformation and ageing of mild steel: III discussion of results. Proc. Phys. Soc. B 64, 747-753. doi:10.1088/0370-1301/64/9/303

Mohamed, I. F., Yonenaga, Y., Lee, S., Edalati, K., and Horita, Z. (2015). Age hardening and thermal stability of $\mathrm{Al}-\mathrm{Cu}$ alloy processed by high-pressure torsion. Mater. Sci. Eng. A 627, 111-118. doi:10.1016/j.msea.2014.12.117

Morito, S., Huang, X., Furuhara, T., Maki, T., and Hansen, N. (2006). The morphology and crystallography of lath martensite in alloy steels. Acta Mater. 54, 5323-5331. doi:10.1016/j.actamat.2006.07.009

Nakada, N., Koga, N., Tsuchiyama, T., and an Takaki, S. (2009). Crystallographic orientation rotion and internal stress in pearlite colony. Scr. Mater. 61, 133-136. doi:10.1016/j.scriptamat.2009.03.028

Okayasu, M., Sato, K., Mizuno, M., Hwang, D. Y., and Shin, D. H. (2008). Fatigue properties of ultra-fine grained dual phase ferrite/martensite low carbon steel. Int. J. Fatigue 30, 1358-1365. doi:10.1016/j.ijfatigue.2007.10.011

Okitsu, Y., Takata, N., and Tsuji, N. (2009). A new route to fabricate ultrafinegrained structures in carbon steels without severe plastic deformation. Scr. Mater.60, 76-79. doi:10.1016/j.scriptamat.2008.09.002

\section{DATA AVAILABILITY STATEMENT}

The raw data supporting the conclusions of this article will be made available by the authors, without undue reservation.

\section{AUTHOR CONTRIBUTIONS}

$\mathrm{M}$-hP was responsible for this research. M-hP and AS carried out most of experiments and analysis. M-hP and NT wrote the paper. All authors discussed the results, and checked and revised the manuscript.

\section{FUNDING}

This work was financially supported by the Elements Strategy Initiative for Structural Materials (ESISM; JPMXP0112101000), JST CREST (JPMJCR1994), and KAKENHI (Grant-in-Aid for Scientific Research from the Japan Society for the Promotion of Science; 15H05767, 19H02459 and 20K14608), all from the Ministry of Education, Culture, Sports, Science and Technology (MEXT), Japan. All the supports are gratefully appreciated.

Petch, N. J. (1953). The cleavage strength of polycrystals. J. Iron Steel Inst. 174, 25-28.

Shibata, A., Daido, S., Terada, D., and Tsuji, N. (2013). Microstructures of pearlite and martensite transformed from ultrafine-grained austenite fabricated through cyclic heat treatment in medium carbon steels. Mater. Trans. 54, 1570-1574. doi:10.2320/matertrans.MH201312

Son, Y. Il., Lee, Y. K., Park, K. T., Lee, C. S., and Shin, D. H. (2005). Ultrafine grained ferrite-martensite dual phase steels fabricated via equal channel angular pressing: microstructure and tensile properties. Acta Mater. 53, 3125-3134. doi:10.1016/j.actamat.2005.02.015

Stolyarov, V. V., Zhu, Y. T., Lowe, T. C., and Valiev, R. Z. (2001). Microstructure and properties of pure Ti processed by ECAP and cold extrusion. Mater. Sci. Eng. A 303, 82-89. doi:10.1016/S0921-5093(00)01884-0

Takahashi, T., Nagumo, M., and Asano, Y. (1978). Microstructures dominating the ductility of eutectoid pearlitic steels. Trans. Jpn. Inst. Met. 42, 708-715.

Tsuji, N., Gholizadeh, R., Ueji, R., Kamikawa, N., Zhao, L., Tian, Y., et al. (2019). Formation mechanism of ultrafine grained microstructures: various possibilities for fabricating bulk nanostructured metals and alloys. Mater. Trans. 60, 1518-1532. doi:10.2320/matertrans.MF201936

Tsuji, N., Kamikawa, N., Ueji, R., Takata, N., Koyama, H., and Terada, D. (2008). Managing both strength and ductility in ultrafine grained steels. ISIJ Int. 48, 1114-1121. doi:10.2355/isijinternational.48.1114

Tsuji, N., Ueji, R., and Minamino, Y. (2002). Nanoscale crystallographic analysis of ultrafine grained IF steel fabricated by ARB process. Scr. Mater. 47, 69-76. doi:10.1016/S1359-6462(02)00088-X

Yin, J., Hillert, M., and Borgenstam, A. (2017). Morphology of proeutectoid ferrite. Metall. Mater. Trans. A 48, 1425-1443. doi:10.1007/s11661-016$3903-y$

Conflict of Interest: The authors declare that the research was conducted in the absence of any commercial or financial relationships that could be construed as a potential conflict of interest.

Copyright (C) 2020 Park, Shibata and Tsuji. This is an open-access article distributed under the terms of the Creative Commons Attribution License (CC BY). The use, distribution or reproduction in other forums is permitted, provided the original author(s) and the copyright owner(s) are credited and that the original publication in this journal is cited, in accordance with accepted academic practice. No use, distribution or reproduction is permitted which does not comply with these terms. 